\title{
Adaptation of Traditional Festivals to Natural Resources Conservation Education: Lessons from Osun-Osogbo and Argungun Fishing Festivals in Nigeria
}

\author{
Adekunle Olatumile $P h D$ \\ Department Of Adult Education \\ Adekunle Ajasin University \\ Akungba-Akoko, Nigeria \\ Tel: +23470650494I I \\ E-mail: kunletumile@gmail.com
}

\begin{abstract}
Africa has been tagged a festival continent as year in year out, towns and villages witness cultural festivals throughout the year. These festivals are mostly concerned with resources conservation and utilization. The adoption of Western Model of conserving biodiversity in the trickle-down fashion has failed to yield reasonable result; whereas traditional festivals epitomize indigenous people's respect and reverence for, and pragmatic understanding of, their natural environment. The quest of conserving biodiversity for sustainable development therefore calls for the integration of traditional festivals in sustainable resource management framework. In spite of the invaluable potentials of traditional festivals in biodiversity conservation as an indigenous resource management system, it has not been given a prominent place in the modern day scientific resource management framework. Using ethnographic research design, the paper exploits the natural resources conservation potentials of OsunOsogbo and Argungun fishing festivals in Nigeria. Data are collected from archival, ethnographic and internet materials, as well as text books, pictures and information through interviews and observations. The paper presents an analysis of ways through which policy frameworks can benefit from festivals and how a wide audience can be reached with biodiversity conservation messages for the purpose of creating awareness. The paper develops a framework for ecosystem based adaptation, using indigenous festivals for the purpose of replicating it in every other community where such festivals do not exist and integrating it in festivals that are not based on natural resource conservation.
\end{abstract}

Keywords: Festival; Environment, Ecosystems; Climate change; Resource management

\section{Introduction}

The issue of environmental protection and sustainability has dominated global discourse lately, and going by unfolding events of natural disasters, it will continue to gain prominence in addressing the problems facing humanity now and in the next centuries. Human beings depend on basic goods and services biodiversity provides for survival. They in most cases exploit biodiversity far beyond basic requirement for survival, they also utilise biodiversity and its goods and services to support 'the acquisition of wealth, development of culture, infrastructure for travel and communication, and many other elements that contribute to the establishment and maintenance of societies (Pirot, Meynell and Elder, 2000). Human being therefore, in the quest of survival and enjoying decent and comfortable life seem to utilize biodiversity in a manner that does not care for those coming behind. This gives rise to the global discourse on biodiversity and ecosystem management for the continued survival of man. Consequently, a lot of strategies for biodiversity conservation have been introduced, of which the traditional approach has been the conservation of species and establishing protected areas. This approach has been fraught with glaring limitations as it has yielded limited result. It has been noted that biodiversity will not be conserved effectively in protected areas alone. The existing global network of protected areas is too small and, under prevailing social and economic conditions, any major expansion of this network seems unlikely. Many existing protected areas are under threat and, even where significant areas have been placed in protected areas, prevailing development patterns are creating barriers to species interaction and migration. The fragmentation of natural habitats has reduced the long term viability of protected areas by making species more vulnerable to genetic erosion and the impact of climate change (Kakababe, 2000).

If the goals of sustainable development are to be achieved there is a dire need to understand the invaluable role of sustainable natural resource conservation strategies that are locally integrated. The Convention on Biological Diversity recognizes that the close and traditional dependence of local and traditional communities embodies traditional lifestyles on biological resources, and the desirability of sharing equitably benefits arising from the use of traditional knowledge, innovations and 
practices relevant to the conservation of biological diversity and the sustainable use of its components. It suggested in article 8 section h, that each contracting party shall, as far as possible and as appropriate subject to its national legislation, respect, preserve and maintain knowledge, innovations and practices of indigenous and local communities embodying traditional lifestyles relevant for the conservation and sustainable use of biological diversity and promote their wider application with the approval and involvement of the holders of such knowledge, innovations and practices and encourage the equitable sharing of the benefits arising from the utilization of such knowledge, innovations and practices (CBD 20I2).

In furtherance of this, the tenth meeting of the Conference of the Parties, held from 18 to 29 October 2010, in Nagoya, Aichi Prefecture, Japan, adopted a revised and updated strategic plan for biodiversity, including the Aichi biodiversity targets, for the 201 I-2020 period, and urged parties and government to develop national and regional targets in the framework of the Aichi biodiversity targets. Target I8 stipulated that: By 2020, the traditional knowledge, innovations and practices of indigenous and local communities relevant for the conservation and sustainable use of biodiversity, and their customary use of biological resources, are respected, subject to national legislation and relevant international obligations, and fully integrated and reflected in the implementation of the Convention with the full and effective participation of indigenous and local communities, at all relevant levels.

One important traditional institution that can be effectively utilised for sustainable biodiversity conservation is festival. Africa has been tagged a festival continent, because year in year out festivals are held almost in every part of the continent. Festival is an occasion for celebrating a day or time of religious or cultural significance that recurs at regular intervals. It is a time people do something that they would normally not do; they abstain from something they normally do; they carry to the extreme behaviours that are usually regulated by measure; they invert patterns of daily social life. Reversal, intensification, trespassing and abstinence are the four cardinal points of festival behavior (Babcock 1978 cited in Mathias 2014).

A perusal of literature shows festival as recurring periodic days or seasons set aside by communities or clans for a celebration or feast, a season of musical or other performances, joyfulness and merry making, observance of sacred celebrations, religious solemnities and traditional performances of special significance, which are an integral part of the African traditional society and functions for societal integration and solidarity (Famuyiwa 1992. Mathias 2014 and Ezenagu \& Olatunji 20I4). Festivals are an integral part of the cycle of life of a traditional African man or woman. From conception to birth and finally death, there is a strong inclination towards festivals which is a traditional institution. These traditional institutions are common to all human societies. Virtually in all African communities, festivities constitute a benchmark for marking various stages tantamount to befitting life. It is one of the ways through which man expresses his awareness of transcendental beings outside himself... festivals are the manifestation of culture in any traditional society. They are entertaining events which offer opportunities for celebrating and learning age long traditions (Ezenagu \& Olatunji 2014). Given the contemporary African environment, festival often possesses elements of unity that is why festival is also a medium of cultural, educational, intergenerational and communicational importance. With this, it is able to play an important role in the preservation of cultural heritage, transmission of knowledge and communal experiences as a people to future generations (Adegbite 2010).

Nwosu (2010) has put in fore the symbiotic connection between natural environment and human survival when he stressed that the natural environment is closely tied to integral human life, and without it, human life may not be sustained. Natural environment includes social, religious, linguistic, economic, and other cultural elements. In fact, the distinct understanding of these elements and their relative values can be closely correlated. Thus, in this 2Ist century, people in various sectors of life are coming to understand the central fact that the natural environment has to be protected and sustained. Juxtaposing this with the submission of Chandra (2012) underscores the invaluable role festivals can play in sustainable resource management in Africa. He maintained that sustainable natural resource management is driven by the beliefs and behaviours of human communities and local cultures are strengthened by their immediate connections to the natural environments that sustain them. Our modern world is often poorer for the scientific rationalism that treats objective and sacred knowledge as different entities, while traditional cultures do not make such distinction. However traditional knowledge based systems could qualify as having conservation value if they satisfy two basic criteria (a) prevent or mitigate resource depletion, species extirpation or habitat degradation and (b) be designed to do so.

\section{Description of Nigeria's Biodiversity}

Nigeria occupies a unique geographic position in Africa and the variability in climate and geographic features endows her with one of the richest biodiversity in the continent. Its diversity of natural ecosystems ranges from semi-arid savanna to mountain forests, rich seasonal floodplain environments, rainforests, vast freshwater swamp forests and diverse coastal vegetation. Nigeria's Niger delta contains the largest tract of mangrove in Africa. The individual components of biodiversity - genes, species, and ecosystems provide our society with a wide array of goods and services. (FRN, 2010).

A country report published in 1992 by the Federal Environmental Protection Agency (FEPA) indicated that Nigeria possesses more than 5,000-recorded species of plants, 22,090 species of animals, including insects and 889 species of birds, and I,489 species of microorganisms. It estimated that $0.4 \%$ of the plant species are threatened and $8.5 \%$ endangered, with $0.14 \%$ 
of the animals and insects threatened and $0.22 \%$ endangered. The country study listed I35 reptilian species, I09 amphibian species and 648 fish species and recognized the forests in Cross River State of Nigeria to be a hotspot for amphibian biodiversity. Nigeria is known as a global hotspot for primate species, with a great diversity found especially in the Gulf of Guinea forests of Cross River State. Some of the endemic species include three monkeys, the white-throated monkey (Cercopithecus erythrogaster), Sclater's guenon (Cercopithecus sclateri) and the Niger Delta red colobus (Procolobus pennantii epieni) and four bird species, the Anambra waxbill (Estrilda poliopareia), the Ibadan malimbe, (Malimbus ibadanensis), the Jos Plateau indigo-bird (Vidua maryae) and the Rock Fire-Finch Lagonostica sanguinodorsalis. The most endangered gorilla subspecies on earth, the Cross River gorilla (Gorilla gorilla diehli) with an estimated population of less than 250 individuals is found only in a couple of protected areas in Cross-River State, south eastern Nigeria. (FRN, 2010). The IUCN Red List of Threatened Species (i.e. of globally threatened species) includes I48 animals and I46 plants that are found in Nigeria. Of these, 26 animals and I8 plants are classified as endangered and another three animals and I5 plants are critically endangered worldwide. (FRN, 2010).

Natural and man-made threats, socio-cultural problems as well as direct and indirect consequences of socio-economic development have contributed to the erosion of biodiversity at all levels. Within the last 25 years, it is believed that about $43 \%$ of the forest ecosystem has been lost through human activities. Nigeria, with a population of over 140 million people constitutes nearly a quarter of the total population of sub-Saharan Africa. A population growth rate of more than $3 \%$ and increasing poverty (especially in rural areas) has put severe demand on the country's natural resources, the institutional structures and the resources available to manage them. There has been a general institutional weakness and lack of technical capacity to effectively tackle the nation's environmental issues, including threat to biological diversity. (FRN, 2010).

\section{Nigeria National Biodiversity Strategy and Action Plan}

The goal of the National Biodiversity Strategy and Action Plan (NBSAP) is 'to develop appropriate framework and programme instruments for the conservation of Nigeria's Biological Diversity and enhance its sustainable use by integrating biodiversity consideration into national planning, policy and decision-making processes. This strategy is part of her commitments under the Convention on Biological Diversity and a testimony to her responsibilities to her future generations. The NBSAP addressed the following areas which have guided Nigeria's various conservation priorities and actions Biodiversity Conservation:

The Nigerian government recognizes the need to conserve its biological diversity and has made a commitment to conserve Nigeria's 25\% of total forest area. Emphasis is placed on in situ conservation of biodiversity within protected areas such as Forest Reserves, Game Reserves, National Parks and Wildlife Sanctuaries. In situ conservation outside protected areas will be encouraged to complement conservation of biological diversity inside protected areas, to secure Nigeria's biodiversity for future generations. Priority attention is placed on conservation of unique ecological characteristics and ecosystems such as mountain, mangrove, wetlands, savanna and rain forests and transit sites for migratory species. (FRN, 20I0).

\section{Conservation of agro-biodiversity}

Due to the diversity of habitats in Nigeria and the tropical climate, there is great diversity of plant species, including several that have been domesticated. Nigeria's plants include many species with traditional value as food items, medicines and for various domestic uses and a number of these have been catalogued in various specific areas of the country. Nigeria is also an epicenter for diversity of wild varieties of important crop plants. A number of these wild crops and their relatives although more adapted to the environment and climate are being replaced with new varieties/cultivars and are therefore threatened with extinction (FRN, 2010). In order to achieve the set goals, Article IO of the NBSAP makes concrete provision for a programme of research, extension and education that will enhance sustainable biodiversity conservation, and thus suggests the "Sustainable use of components of biological diversity especially the aspects concerning the protection and encouragement of customary use of biological resources in accordance with traditional cultural practices that are compatible with conservation and sustainable use requirements" (FRN, 2010).

\section{Traditional Festivals as Means of Biodiversity Conservation}

Every region of Nigeria has at least one major festival that attracts tourists all over the World. These festivals are mostly concerned with resources conservation and utilization, maintaining and promoting traditional life. Thus traditional festivals celebrate issues that border on occupation like fishing, hunting and farming. Some other traditional festivals are built around the preservation of the sanctity of sacred geographies and sacred natural sites like land, mountain, forests, rivers and so on. Traditional respect for the environment and access restrictions to sacred sites have often led to well-conserved areas with high biological diversity within otherwise degraded environment (Sheat 2003 cited in Negi 2010). Traditional festivals sustain existing cultural beliefs and social practices that include sacred groves/forest, water, land, wildlife conservation, resource utilization taboos, folktales and traditional religion in most Nigerian societies. Through such beliefs and practices, traditional knowledge and indigenous environmental wisdom which is part of the corpus of African indigenous knowledge system (AIKS) 
in such communities, have been passed on from generation to generation (Soola, 2009). Cultural diversity in these communities is closely linked to biodiversity, as there is a symbiotic relationship between ecosystem and cultural identity, Indeed religious rules and rituals often strengthen this relationship and they are characterized by conservation ethics (Negi, 20I0). Traditional festivals epitomize indigenous people respect and reverence for and pragmatic understanding of their natural environment. The quest of conserving biodiversity for sustainable development therefore calls for the integration of traditional festival in the sustainable resource management framework. In spite of the invaluable potentials of traditional festivals in biodiversity conservation as an indigenous resource management system, it has not been given a prominent place in the modern day scientific resource management framework. Whereas in traditional societies, sustainable natural resource management is driven by the beliefs and behaviours of human communities, and local cultures are strengthened by their intimate connections to the natural environment that sustains them. Our modern world is often poorer for their scientific rationalism that treats objective and sacred knowledge as separate spheres. While traditional cultures do not make such distinctions (Negi, 2010). Hence a deliberate attempt to case study African indigenous festivals that will model the integration of this important indigenous knowledge system into the country's resource management framework is germane. This is where the two prominent festivals of conservation significance, the Osun Osogbo festival and Argungun fishing festival used as reference points in this work, play an important role.

\section{Osun Osogbo Festival}

Osun Osogbo festival is celebrated annually in Osogbo the capital of Osun State in South-Western Nigeria. It holds at the end of every second quarter of the year and normally lasts four weeks. The festivities take place in the Osun sacred grove, which according to UNESCO is the largest and perhaps the only remaining example of a once widespread phenomenon that used to characterise every Yoruba settlement. It now represents Yoruba sacred groves and their reflection of Yoruba cosmology. It is a tangible expression of Yoruba divinatory and cosmological systems; its annual festival is a living thriving and evolving response to Yoruba beliefs in the bond between people, their ruler and the Osun goddess.

The grove covers 75 ha of ring-fenced forest alongside the Osun River on the outskirts of Osogbo town, Western Nigeria. About 2 million people live in Osogbo. The grove in Yoruba cosmology is the domicile of Osun, the goddess of fertility. Ritual paths lead devotees to forty shrines, dedicated to Osun and other Yoruba deities, and to nine specific worship points beside the river. Osun is the Yoruba personification of the 'waters of life' and the spiritual mother of the Osogbo township. It also symbolizes a pact between Larooye, the founder of Osogbo, and Osun the goddess that gave prosperity and protection to her people if they built a shrine to her and respected the spirit of the forest. Unlike other Yoruba towns whose sacred groves have atrophied, or disappeared, the Osogbo Grove has, over the past forty years, been re-established as a central, living focus of the town. The Osogbo Grove is now seen as a symbol of identity for all Yoruba people, including those of the African diaspora, many of whom make pilgrimages to the annual festival (UNESCO, 2005). In 2005 the grove was listed in UNESCO world heritage list.

The grove has a mature, reasonably undisturbed, forest canopy, which supports a rich and diverse flora and fauna including the endangered white-throated monkey. Some parts were cleared in the colonial period, and teak plantations and agriculture introduced, but these are now being re-established. The grove is a highly sacred sanctuary where shrines, sculptures and artworks honour Osun and other Yoruba deities. It has five main sacred divisions associated with different gods and cults, located either side of a path transecting the grove from north-west to south-east. The Osun River meanders through the whole grove and along its length are nine worship points. Throughout the grove the broad river is overhung with forest trees. Its waters signify a relationship between nature, the spirits and human beings, reflecting the place given to water in the Yoruba cosmology as symbolizing life. The river is believed to have healing, protective and fertility powers. The fish are said to have been used by the goddess Osun as messengers of peace, blessings and favour. (UNESCO, 2005).

The Annual Osun-Osogbo festival is a 12-day event held once a year at the end of July and the beginning of August. The grove is seen as the repository of kingship, as well as the spiritual heart of the community. The grand finale of the festival is a procession of the whole population, led by the votary maid Arugba and headed by the Oba and priests, all accompanied by drumming, singing and dancing.

\section{Argungun Fishing Festival}

The Argungu Fishing Festival is the culmination of a four-day cultural event in the North-Western Nigerian state of Kebbi. The state is naturally endowed with rivers such as the Niger and Rima that enhance fisheries activities, which have been one of the main occupations of the people of the State (Asogwa, Umeh and Okwoche 20I2b). The festival is a tool for conserv ing natural resources, maintaining and promoting traditional life....the effective conservation of natural resources is closely linked to the use of the local knowledge and hence the life of the community. (Asogwa, Umeh and Okwoche 20I2a and Asogwa, Umeh and Okwoche 2012b). The festival marks the end of the growing season and the harvest. A one mile (I.6 kilometer) stretch of the Argungu River is protected throughout the year, so that the fish will be plentiful for this one hour fishing competition. More 
than 30,000 fishermen had taken part in this annual festival. People from all over West Africa have come to participate in the fishing contest in the waters of the river mata fada, using nets and traditional gourds made with calabashes a sort of pumpkin dried and hollowed. The fisherman who catches the biggest fish wins a prize of 7000 dollars. Thousands of fishermen line up like an ancient army, carrying their traditional nets and gourds. At the sound of a gun, they pound towards the narrow river and leap into the water. They have just one hour to catch the biggest fish. Fishermen only come here once a year on the day of the festival. At the end of the hour, the competitors have their fish piled up at the foot of the weighing machine and are tagged and weighed.

The fishing festival has continued as an annual event, with additional cultural and sporting activities, attracting about five hundred thousand spectators from all over Nigeria, and all over the world. It also attracts local and international media coverage, including the CNN and BBC (Dantata, 2007 cited in Asogwa, Umeh and Okwoche 2012b). Tourists and guests for the occasion troop in large numbers from Europe, Britain, United States, Russia, South East Asia, and neighbouring African countries like Niger, Benin Republic, Cameroon, etc. Cultural troupes and Heads of Missions of most nations that attended FESTAC '77 also witnessed the festival. Almost all Nigerian Heads of State and Presidents have witnessed the festival.

\section{Biodiversity Resources Conserved through the Festivals}

The Osun Osogbo and Argungun Fishing Festivals have engendered conservation of a diverse variety of flora and fauna which ordinarily would have been impaired by human activities. The forest canopy in the heart of Osogbo, a state capital in South West Nigeria, is a scene to behold. There is no city that can parade such biodiversity infrastructure in Nigeria. The osun river that meanders through the forest is in its natural state as no human activities is allowed therein, the wide variety of trees and other plants adorn the forest. Some of the trees and plants may not be found around the communities as they must have been depleted. The grove also accommodates different varieties of animals which visibly include bats and the white mouthed monkey that is classified as endangered. The land in the grove is still reasonably intact as it is not prone to either wind or water erosion. To crown it all, no human activities is allowed in the grove, it is totally forbidden. The beauty of it is that, without any security architect created to enforce this, no person dare enter the grove to contravene this taboo as spirituality is attached to everything about the grove and the festival.

The river mata fada is conserved throughout the year as result of the festival, because at the end of the festival a reasonable stretch of the river is restricted from fishing activities so as to prepare the river for another bountiful harvest the following year. Apart from the stretch of the river that is conserved, the ripple effect of the conservation will extend far beyond the one mile stretch, since it is not possible to moderate the migration of fishes in the river. It is also reasonable to conclude that no unsustainable fishing method will be in use in the river, for example no one will dare use chemical to kill fish as the pollution effect may travel as far as the river stretches. The materials used in catching fish in itself is sustainable; they are traditional nets and gourds that do not easily bring about degradation of the fish resources. In the same vein the materials are climate change compliant, because they do not undergo rigorous manufacturing process that can bring about carbon emission. The water of the river is also conserved because any human activities that can bring about pollution which may eventually affect the availability of fish is prohibited.

\section{What is the place of Festivals in Biodiversity Conservation Presently?}

Effort geared towards biodiversity conservation in Nigeria has not fully tapped in to the potent power of festival in biodiversity conservation strategy. This is borne out of the fact that African adherents of the modern religion especially Christians and Muslims associate traditional festivals with idolatry and hence hold it in contempt. Governments and Non-Governmental Organisations do not mainstream festivals in their quest to find solution to the resource depletion facing African biodiversity. The "elites" in the African society disparage traditional festivals which they see as the exclusive preserve of the not too educated in western education in the society hence the dwindling fame of traditional festivals in the continent.

\section{Way forward}

The quest for conserving biodiversity for sustainable development requires the integration of traditional festivals in sustainable resources management framework. Traditional festivals of conservation implication need to be given official recognition by State and Local governments. There should be a synergy between the Ministries of Culture and Environment to give a boost to these festivals and should be allocated fund in their budgets. Non-Governmental Organisations must mobilise all stakeholders in awareness creation on the import of festivals in biodiversity conservation. Local Governments should liaise with traditional rulers who are the custodians of traditional festivals to identify festivals that are resources focused and how resource conservation can be mainstreamed into other festivals. National biodiversity strategy and action plans in Nigeria should mainstream festivals as part of its strategies.

Modern religion festivals that are conservation related should be given a boost by all stakeholders. All the major religions have resource conservation inherent in them; this should be harnessed mutually in the resource management framework. 
Instead of condemning one another. Government functionaries, traditional leaders and religious leaders should operate synergiously to tap the invaluable role festival plays in resource management. Christians and Muslims should be made to acknowledge the fact that there are festivals and injunctions in their faith that is conservation specific. For instance the year of jubilee stipulates that when the Israelites cultivate a land for six years the seventh year is the year of jubilee when the land should be allowed to rest, in the same vein they were instructed that when a city is attacked they can destroy everything but fruit trees should not be cut. Islam has variously injunctions concerning sustainable use of water. Muslims have a tradition of planting trees in their burial grounds and it forbidden for anyone to use any part of the tress for any purpose, hence it implies that human activities is not allowed in the burial grounds.

There are communities that may not have festivals that are directly related to biodiversity conservation, festivals that are directly linked with resource conservation should be replicated in communities where they do not exist. Conservation related festivals should be modernized with lectures environmental advocacy and media adequately harnessed to boost them.

Modern Information Communication Technology should be fully harnessed in publicizing these festivals so that by this they can be popularized. These festivals when uploaded in youtube, instagram, facebook and other social media will attract more recognition and support.

\section{References}

Asogwa B C, Umeh J C and Okwoche V A (2012a) The Sociological and Cultural Significance of Argungun International Fishing Festival in Nigeria. International Journal Humanities and Social Sciences 2(I I):243-249

Asogwa B C, Umeh J C and Okwoche V A (2012b) Community Fishing and the economics of Argungun Fishing Festival in Nigeria. Asian Journal Business Management 4(2):192-199

Convention on Biological Diversity (2012) Text on the Convention on Biological Diversity. Retrieved on January 52012 from www.cbd.int/convention.text

Ezenagu N and Olatunji T (2014) Harnessing Awka Traditional Festival for Tourism Promotion Global Journal of Arts Humanities and Social Sciences .2 (5) pp: 43-56, June 2014

Federal Republic of Nigeria (2010) Forth National Biodiversity Report. Abuja, Federal Government Press.

Kakabe Y N (2000) Foreword in Pirot J Y,Meynell P J and Elder D (eds) (2000) Ecosystem Management: Lessons from around the World, Switzerland, IUCN.

Mathias B A (20I4) Socio-Religious Significance of Ikoro and Ekpe Festivals in Akwete Ndoki Community of Abia State, Nigeria International Journal of Social Science and Humanity, 4, (5), September 2014

Negi C. S. (2010) Traditional Culture and Biodiversity Conservation: Examples from Uttakharan, Central Himalaya. International Mountain Society.

Nwosu P U (2010) The Role of Okonko Society in Preserving Igbo Environment. Journal of Human Ecology, 3I(I): 59-64

Pirot J Y, Meynell P J and Elder D (eds) (2000) Ecosystem Management: Lessons from around the World, Switzerland, IUCN.

Sinclair F L and Walker D H, (1999) A Utilitarian Approach to the Incorporation of Local Knowledge in Agro-Forestry Research and Extension in: Buck L E, Lassole J P, Femandes E C M (eds) Agro-Forestry in Sustainable Agricultural System Boca Raton, F L: CRC Press pp 245-276,

Soola E O (2009) Communication and Educational Approaches and Strategies for Forest Management: Implications for Africa. European Journal of Social Sciences. 9(3), 2009

UNESCO (2005) Osun-Osogbo Sacred Grove, UNESCO World Heritage Centre. Retrieved on January 42012 from whe, unesco.org $>$ culture $>$ world heritage centre

Walker, D h; Sinclair F L; Joshi L; Ambrose B(I997) Prospect for the use of Corporate Knowledge Bases in the Generation, Management and Communication of Knowledge at Systems 54(3):29I-3I2

\section{Copyrights}

Copyright for this article is retained by the author(s), with first publication rights granted to the journal. This is an open-access article distributed under the terms and conditions of the Creative Commons Attribution license (http://creativecommons.org/licenses/by/4.0/). 